\title{
Family History Tools in Primary Care: Does One Size Fit All?
}

\author{
B.J. Wilson ${ }^{a} \quad$ J.C. Carroll ${ }^{b} \quad$ J. Allanson ${ }^{c} \quad$ J. Little H. Etchegary $^{\text {e }} \quad$ D. Avard ${ }^{f}$ \\ B.K. Potter ${ }^{a}$ D. Castle ${ }^{\text {g }} \quad$ J.M. Grimshaw ${ }^{d}$ P. Chakraborty ${ }^{c}$ \\ a University of Ottawa, Ottawa, Ont., b Mt. Sinai Hospital, Toronto, Ont., ${ }^{c}$ Children's Hospital of Eastern Ontario and \\ ${ }^{d}$ Ottawa Hospital Research Institute, Ottawa, Ont., ${ }^{e}$ Memorial University, St. John's, Nfld., and f McGill University, \\ Montreal, Qué., Canada; ' IUniversity of Edinburgh, Edinburgh, United Kingdom
}

\section{Key Words}

Disease risk assessment • Family history • Family practice • Primary care

\begin{abstract}
Family health history ( $\mathrm{FHH})$ has potential value in many health care settings. This review discusses the potential uses of FHH information in primary care and the need for tools to be designed accordingly. We developed a framework in which the attributes of $\mathrm{FHH}$ tools are mapped against these different purposes. It contains 7 attributes mapped against 5 purposes. In considering different $\mathrm{FHH}$ tool purposes, it is apparent that different attributes become more or less important, and that tools for different purposes require different implementation and evaluation strategies. The context in which a tool is used is also relevant to its effectiveness. For FHH tools, it is unlikely that 'one size fits all', although appreciation of different purposes, users and contexts should facilitate the development of different applications from single $\mathrm{FHH}$ platforms.

Copyright $\odot 2012$ S. Karger AG, Basel
\end{abstract}

\begin{tabular}{ll}
\hline KARGER & $\begin{array}{l}\text { (c) 2012 S. Karger AG, Basel } \\
1662-4246 / 12 / 0154-0181 \$ 38.00 / 0 \quad \text { Karger }\end{array}$ \\
E-Mail karger@karger.ch & This is an Open Access article licensed under the terms of \\
www.karger.com/phg & $\begin{array}{l}\text { the Creative Commons Attribution- NonCommercial-No- } \\
\text { Derivs 3.0 License (www.karger.com/OA-license), applica- } \\
\text { ble to the online version of the article only. Distribution for } \\
\text { non-commercial purposes only. }\end{array}$
\end{tabular}

\section{Introduction}

Family health history (FHH) has always been 'a core element of clinical care' [1]. It is widely recognized as offering insight into the shared genetic, environmental and cultural factors within families, which together influence an individual's susceptibility or resilience to many medical conditions [2]. It is suggested that systematically collecting and using FHH information may contribute to personalized health care $[1,3]$. However, the empirical evidence is currently inadequate to draw conclusions about the actual utility of $\mathrm{FHH}$ tools in routine practice $[1,4-6]$. The main problem was summed up in a systematic review [4], which '... failed to identify a simple generic tool which can be immediately applied in primary care ... Each of the [family history questionnaires] included in the review represents a unique tool and thus presents different ways of wording questions relating to family history. There was no congruency regarding the manner in which family history questions were framed ....

An ideal FHH tool would be simple and versatile and applicable to a number of different clinical purposes. However, we suggest that the diversity of these purposes 
means that a uniform tool may not be realistic: the specific attributes of FHH information and the context surrounding its collection vary by each purpose, raising a challenge for the clinician motivated to try to integrate it into routine practice. The goal of this paper is to discuss these potential uses from a primary care perspective, emphasizing the need to relate design and implementation to intended purpose. We propose a simple framework which may be useful in guiding future evidence syntheses, the development and evaluation of new FHH tools and their effective implementation in practice.

\section{Information versus Tools}

Many publications on the topic of $\mathrm{FHH}$ tools have focused on information rather than tools. This ignores practicalities of data collection and interpretation, and assumes that providers have easy access to sufficiently complete and accurate information for their clinical purposes. In a review of cancer family history tools, a FHH tool was defined as 'a systematic and coherent approach used to capture and document family history, appropriate for the clinical setting, with the potential to lead to decision-making by a clinician' [7]. While this draws attention to the ways in which FHH might be captured, it does not address the purposes for which the information might be used. In an effort to expose the complexity underlying FHH collection, we examined the different purposes for which collection of $\mathrm{FHH}$ has been suggested and identified the general attributes implied by these uses (table 1). We suggest that this illuminates important issues for their design, implementation and evaluation.

The columns in table 1 indicate the purposes to which FHH information might be put, and rows describe the general attributes which $\mathrm{FHH}$ tools might possess.

This kind of mapping highlights potential differences between tools with different purposes and provides a framework to guide issues of design and evaluation of utility. It recognizes different types, extent or detail of FHH and other individual information (the information component') as well as other necessary components and/ or linkage with other resources. Implementation in practice also needs to consider the target population, how the tool is meant to fit with clinical activities and the patient's life course (e.g. what would trigger its use in a particular setting), whether the information needs to be updated, and how much it might demand of professionals in terms of time and expertise or training.
Tools Designed to Capture and Store FHH

Information for Future Use: 'FHH Medical Database

Tools'

This category comprises tools intended to facilitate the collection and storage of FHH information so that it can be retrieved at a later date for disease risk assessment [3]. A truly generic medical database tool would need to capture sufficiently comprehensive information to permit a wide range of purposes (see below).

On the face of it, capturing detailed FHH information should be fairly straightforward, given enough time and an appropriate training [8]. It is generally suggested that FHH medical database tools should be integrated with electronic or personal health records (EHR/PHR) [9]. A consensus-based FHH minimum core data set has been proposed [3], which takes into account the needs for standardization and interoperability between different EHR systems (online supplementary box 1 , for all online suppl. material see www.karger.com/doi/10.1159/000336431). As well as considering the necessary items of information, this proposed data set also highlights the importance of such systems being able to handle unknown or uncertain data, allowing patients to restrict access to sensitive fields, and of considering confidentiality, privacy and security issues.

However they are integrated into EHR/PHR systems, FHH medical database tools need to address important barriers to use in primary care practice $[10,11]$. Most important are the time and resources needed to capture the data, requiring a consideration of how a tool fits into practitioner workflow. Thus, while their technical development currently receives much attention [9], the likelihood of accurate, complete and timely data collection will depend on time pressures in busy practices and perceptions that the benefits are worth the effort. Requiring patients to assemble structured $\mathrm{FHH}$ information in advance is a common practice; there is no evidence that this leads to less accurate information than practitioner-oriented tools, and it may even promote more complete information if patients have time to approach their relatives to find out more [11]. In addition, asking patients to take responsibility for data collection could encourage personal ownership of FHH information and, more broadly, their own health issues.

The medical database approach to $\mathrm{FHH}$ collection may be particularly helpful to multi-professional health teams, in terms of shared data gathering as well as shared access. However, it is also possible that the 'dataset approach' to FHH may negate its utility for some practitioners. The narrative approaches used in traditional pa- 
Table 1. Family history tools development and evaluation framework

\begin{tabular}{|c|c|c|c|c|c|}
\hline \multirow[t]{2}{*}{ Attribute } & \multicolumn{5}{|l|}{ Purpose } \\
\hline & FHH medical database & genetic case finding & $\begin{array}{l}\text { complex disease risk } \\
\text { assessment }\end{array}$ & health promotion & $\begin{array}{l}\text { family systems } \\
\text { genogram }\end{array}$ \\
\hline Target population & All & $\begin{array}{l}\text { Clinical suspicion, patient } \\
\text { concern }\end{array}$ & Large patient groups & $\begin{array}{l}\text { All, related to life } \\
\text { course? }\end{array}$ & All? \\
\hline FHH information & Core data set & Depends on target condition & Simpler? & $\begin{array}{l}\text { Sufficient for risk } \\
\text { stratification? }\end{array}$ & Variable \\
\hline Other information & $\begin{array}{l}\text { Available through } \\
\text { EHR/PHR? }\end{array}$ & Generally less important & $\begin{array}{l}\text { Other clinical } \\
\text { information important }\end{array}$ & $\begin{array}{l}\text { Other health } \\
\text { information important }\end{array}$ & $\begin{array}{l}\text { Family, relationships, } \\
\text { social, emotional, etc. }\end{array}$ \\
\hline Timing of use & $\begin{array}{l}\text { Any. Suited to new } \\
\text { patient intake, } \mathrm{PHE}\end{array}$ & $\begin{array}{l}\text { Responsive to concerns, life } \\
\text { stage? }\end{array}$ & $\begin{array}{l}\text { PHE, clinical suspicion, } \\
\text { patient concerns }\end{array}$ & PHE, opportunistic & $\begin{array}{l}\text { Response to concerns, } \\
\text { life stage? }\end{array}$ \\
\hline Need for updating & Yes & Less important & Yes. Linked to PHE? & Less important? & $\begin{array}{l}\text { Unclear. Continuing } \\
\text { evolution over time? }\end{array}$ \\
\hline Linkage with other tools & EHR/PHR, CDSS & $\begin{array}{l}\text { Referral/testing guidelines, } \\
\text { CDSS }\end{array}$ & $\begin{array}{l}\text { Clinical practice } \\
\text { guidelines }\end{array}$ & $\begin{array}{l}\text { Effective behavior } \\
\text { change interventions }\end{array}$ & - \\
\hline Resources required & $\begin{array}{l}\text { Valid data capture tools, } \\
\text { efficiency important }\end{array}$ & $\begin{array}{l}\text { Valid risk criteria, time, } \\
\text { confidence }\end{array}$ & $\begin{array}{l}\text { Valid risk criteria, time } \\
\text { efficiency important }\end{array}$ & $\begin{array}{l}\text { Unclear, relates to } \\
\text { behavior change } \\
\text { intervention? }\end{array}$ & Time, training \\
\hline
\end{tabular}

$\mathrm{PHE}=$ Periodic health examination; EHR = electronic health record; PHR = personal health record; CDSS = clinical decision support system $(\mathrm{s})$.

tient charts, while often inaccurate and incomplete [12], may actually embed useful contextual information and facilitate meaningful communication with colleagues [9]. Also, some practitioners may use the process of assembling complex information to help them make sense of it, in which case it cannot be replaced by a patientspecific list of statistical disease risks or a preassembled pedigree.

Tools Designed to Use FHH Information in Identifying Need for Specialist Genetic Assessment: 'Genetic Case Finding Tools'

The purpose of genetic case finding is to identify those individuals whose FHH suggests they warrant referral for specialist genetics assessment $[10,13]$. Such tools may be generic or disease-specific, and applied to large patient groups in a screening approach, or more selectively in response to clinician or patient concerns. For example, generic tools may include both lists of genetics 'pearls' [14] or FHH 'red flags' (e.g. early age of onset of common disorders, multiple affected relatives, multiple stillbirths, or spontaneous abortions [14-16]) and tools designed for application to particular populations, for example, children [17] or pregnant women [18]. Specific disease-oriented tools are exemplified by FHH-based guidelines such as the U.S. Preventive Services Task Force recom- mendations for referral for genetic counseling of women with particular familial cancer patterns [19].

While they vary according to the disease and target population, the FHH information components of case finding tools should be those which optimize clinical validity (ability to select patients whose probability of an underlying genetic predisposition exceeds a given threshold) but are also practical for routine use. The usual signals of possible genetic risk are often simple - not only number of affected relatives, but also age of onset, lineage and clustering of different conditions. Designing a 'red flag' tool intended for application to all infants in a busy well baby clinic would need to prioritize simplicity and speed of application, whereas tools to be used selectively in response to individual patient concerns could be more extensive.

Clinical validity implies that the FHH information component of case finding tools meaningfully separates patients who require further action from those who do not. Evaluating this component requires some agreement on what constitutes 'appropriate' action (e.g. referral to genetics or high risk clinic), given that the $\mathrm{FHH}$ in isolation is unlikely to be highly diagnostic for most people. This suggests that geneticists and primary care practitioners should collaborate on defining agreed 'thresholds for action', which then form the basis for audit and evalu- 
ation. The notion of case finding suggests a goal of optimizing sensitivity (the ability to detect all true cases). However, in some situations the purpose may be to select only those individuals who meet predefined criteria for risk, to avoid unnecessary harmful or costly intervention or to ensure that limited clinical resources are not overwhelmed by unmanageable demand [20, 21]. Redefining genetic case finding as a primary care-specialist 'interface tool' emphasizes the importance of communication and mutual agreement about the goals of such tools within the particular health system; focusing on this aspect may promote greater clinical utility than confining attention to the specific $\mathrm{FHH}$ items for inclusion.

There are many 'family history tools' which fall into the genetic case finding category, for example the GRAIDS software [22]. The proliferation of multiple disease-specific tools is a significant barrier to their uptake in primary care: even though genetic predisposition may underlie many common conditions, any single suspected condition may present infrequently in generalist practice (e.g. 3-4 times a year for familial breast-ovarian cancer), and patients often present with more than one problem. Trials of cancer-specific tools have noted acceptable recruitment rates of primary care physicians, but lower levels of use in practice $[22,23]$. The integration of genetics case finding tools with $\mathrm{FHH}$ medical database tools and EHRs to form rapidly accessible, point-of-care tools may overcome these difficulties.

\section{Tools Designed to Use FHH Information in}

Stratification of Complex Disease Risk: 'Complex

Disease Risk Assessment Tools'

In contrast to the case finding approach, complex disease risk assessment tools use FHH information to stratify individual disease risk in order to appropriately target risk reduction interventions. This approach is not so much concerned with identifying people at possible genetic risk than in integrating $\mathrm{FHH}$ into primary carebased chronic disease prevention and management. Applied to large population groups, even small improvements in risk stratification could translate into more effective targeting of preventive interventions and therefore into important absolute gains in population health outcomes [17, 24]. Complex disease risk assessment tools may be based on $\mathrm{FHH}$ alone or integrate FHH information with other kinds of clinical information. Many chronic disease clinical practice guidelines mention the importance of family history and some include FHH specifically as part of risk assessment algorithms [25].
Like case finding tools, complex disease risk assessment tools should achieve useful levels of clinical validity: the ability to correctly stratify individual patients' risk levels. It should be possible to evaluate their performance in terms of sensitivity and specificity, likelihood ratios and accuracy of risk reclassification. Since these tools are applied to relatively large patient groups, and may address multiple conditions, economy of information is important - how much FHH information is 'good enough' for meaningful risk classification when added to standard risk factor information [1]? The goal of complex disease risk assessment tools is to promote appropriate, evidencebased clinical actions, such as personal lifestyle advice, clinical investigations, prescribing guidance, and/or referral for further investigation or specialist assessment. Referral for genetics assessment may be appropriate, but not the main focus of the tool.

There is little published evidence on the 'added value' of FHH information to standard risk factor assessment. Hariri and colleagues [26] used cross-sectional self-report national survey data to assess whether FHH was a predictor of self-reported diabetes status. The results suggested that a respondent's report of a FHH of diabetes had a sensitivity and specificity of 73 and $68 \%$, respectively, for predicting self-report of diabetes diagnosis. Figures 1a and $b$ show how the test metrics alter when information on FHH and another risk factor, obesity, are combined. They illustrate that, if the goal is to maximize identification of affected individuals (prioritizing sensitivity), then it is logical to classify as 'positive' anyone who has a positive $\mathrm{FHH}$, or is obese or both (fig. 1a). In contrast, if the purpose is to minimize the false-positive rate (perhaps because of costly diagnostic tests), then a definition requiring a positive $\mathrm{FHH}$ and being obese maximizes the positive predictive value (fig. 1b) [26].

From a practice perspective, complex disease risk assessment tools may not look like 'family history tools' because they are, in effect, versions of clinical practice guidelines. While this might promote their implementation in practice, it emphasizes the need to clarify how much FHH information is 'enough information', how it is incorporated into disease risk stratification in a valid way and how this should be reflected in specific clinical recommendations.

Tools Designed to Use FHH Information to Help Promote Desirable Health Behaviors: 'FHH Health

Promotion Tools'

Collecting FHH and using it to personalize risk information for patients is thought to be a useful way to moti- 
vate positive health behaviors [1]. The 'health promotion' $\mathrm{FHH}$ tool would be designed not only to capture $\mathrm{FHH}$ information, but also use it to facilitate health changes (lifestyle behaviors, clinical preventive activities and compliance with recommended treatment). There is very limited evidence to support the effectiveness of such tools. The Family Healthware ${ }^{\mathrm{TM}}$ Intervention Trial [27] showed that self-completion of a FHH questionnaire and personalized feedback for several chronic conditions led to small improvements in physical activity and consumption of fruit and vegetables, but not changes in other target health behaviors, although a high proportion of participants were already at their prevention goals at baseline. Other studies of $\mathrm{FHH}$ and behavior change have generally used inadequate study designs $[28,29]$. A neglected issue is the apparent 'black box' approach to the psychological mechanism by which familial risk information might alter health behavior [29].

In considering such tools, it is necessary to distinguish the 'information' and 'behavior change' components. A common starting point seems to be an information component that focuses on the FHH items needed for accurate disease risk assessment [30]: this implies that patients adopt a logical and systematic processing approach to risk information [31] and that inaccuracies in the risk assessment may undermine efforts to promote behavior change. This neglects a number of theories which suggest that the processing of threatening health information has prominent emotional elements and that people may reach 'personally believable' risk assessments which are well out of line with objective estimates. This is especially important where shared experiences lead to 'family beliefs' about risk which defy professional interpretation [32-37]. Thus, a useful FHH health promotion tool might depend more on incorporating $\mathrm{FHH}$ information effectively in an appropriate behavior-change theory, than on a primary focus on the accuracy of statistical risk assessment.

An alternative strategy for $\mathrm{FHH}$ health promotion tools may lie in translating evidence on successful behavior change interventions from other areas in health research, e.g. physical activity or smoking cessation, rather than concentrating solely on the accuracy of risk stratification or pursuing a very distinct 'familial' approach. Perhaps uptake and implementation would be more successful if practitioners and patients see such tools as being about 'health' rather than FHH. McBride et al. [38] have suggested that the 'motivational potency' of risk information might be amplified by considering the individual within the family, i.e. considering the salience of the information and the 'natural synergies' which might pro-

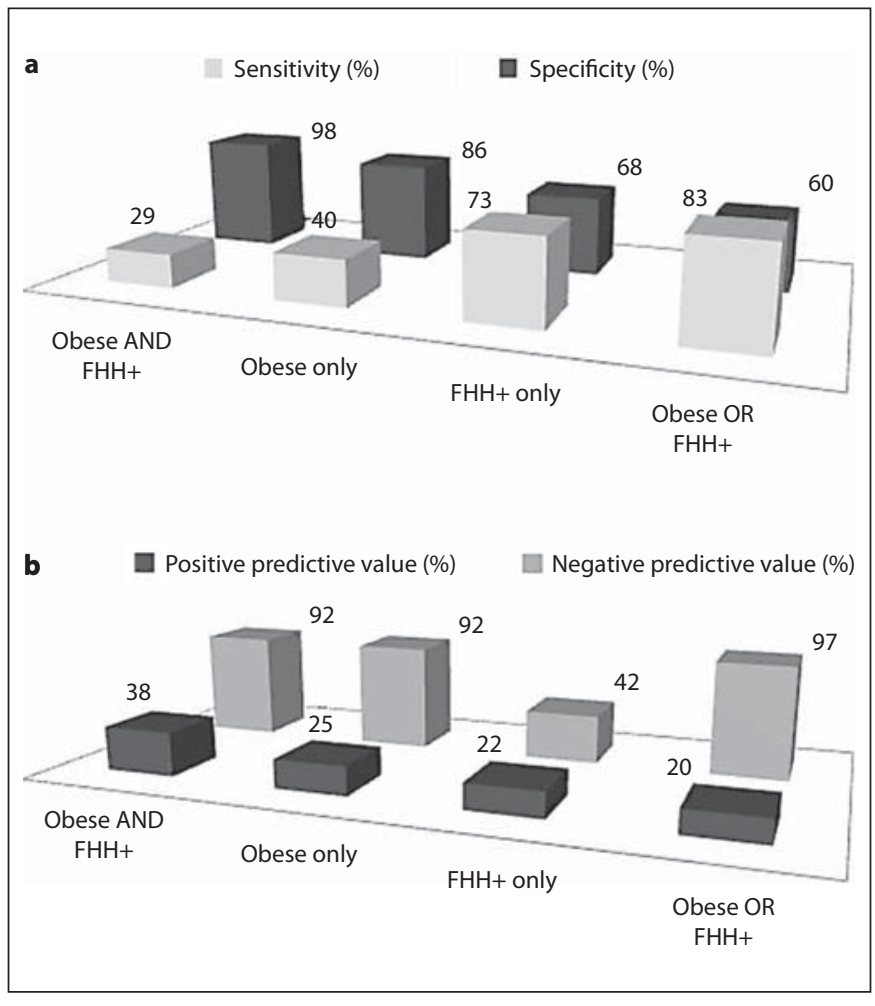

Fig. 1. Clinical validity metrics for FHH combined with selfreport of obesity for detecting diagnosis of diabetes [26].

mote and sustain behavior change. This shift in emphasis offers intriguing possibilities for novel approaches in this challenging area.

Tools Designed to Integrate FHH Information in a Broader Family Systems Assessment: 'Family Systems Genogram'

Originally developed as a tool derived from family systems theory [39], the genogram is distinct from the genetic pedigree [8] in that it incorporates information on family relationships, dynamics and psychosocial issues [40]. It has been described as a 'biopsychosocial family tree' that helps reveal 'important family patterns of illness, disease, and psychosocial problems' [41]. The purpose of this type of tool is to integrate $\mathrm{FHH}$ information within a broad, inclusive and holistic assessment of a patient as a member of a family to facilitate a deeper and richer understanding of a 'family's past and present attitudes and beliefs about genetic risk' [42] and to help identify potential issues faced by a patient in dealing with disease, disease risk, behavior change, compliance with management recommendations, and communication 
with relatives [42-45]. The genogram idea may fit very well with the perspectives and practices of many primary care physicians, with its orientation towards integration of information, attention to psychosocial issues and both individual- and family-centeredness [44].

The genogram approach has been used by enthusiasts for several decades and comprises standard pedigree drawing along with a range of extra annotations to represent the nature of the personal relationships between family members and freehand comments on issues viewed as relevant by the practitioner (online suppl. fig. 1, www.karger.com/doi/10.1159/000336431). If viewed as a method of summarizing and communicating information between health care providers [42], it requires a common approach to notation. However, from a counseling perspective, its value may lie in process as much as outcome, i.e. it is in the collaboration between patient and provider in working through, drawing and populating the pedigree that the less obvious but important issues emerge. Understood in this way, the notion of a sufficient and standalone 'tool' is inadequate for this type of FHH intervention, where the 'doing' is part of the tool.

Although the genogram has been available since the 1980 s, it has not been subject to rigorous evaluation through well-designed controlled trials. This detailed approach to data collection, and the implication of a counseling approach in its construction, suggests an element of initial training, and a nontrivial demand on consultation time if used comprehensively. Even with clear evidence of benefits, and despite its consonance with familycentered primary care [46], the wide implementation of a genogram-based approach would face a significant barrier in the time commitment it demands. It also represents a notion of $\mathrm{FHH}$ which is entirely different from the systematic, 'rational' quantitative process implied in some of the tools described above. Greater clarity is needed on what benefits the genogram approach might bring if used systematically as an enhanced approach to FHH in primary care, a discussion which might profitably be linked to the discussions of the other FHH tools above.

\section{Discussion}

Whatever its purpose, a 'FHH tool' is a complex intervention, i.e. one which achieves its intended effect through the combined action of several different components [47, 48]. Each tool needs consideration of its technical com- ponents (e.g. specific information items, algorithms/recommendations), its target users (especially their prior knowledge, skills, attitudes, confidence, etc.), its specific implementation format (e.g. paper, electronic, phonebased), its integration into existing care pathways, and what is to be done with the 'output'. Many recent studies focus on the informational components of $\mathrm{FHH}$, but evidence from well-designed trials is limited and highlights the need to consider the entire intervention, not just the FHH content. The user perspective is important because this affects the quality of data, therefore the validity of risk analyses. As important is the purpose: FHH tools will languish largely unused if practitioners do not really know why they are collecting structured information, do not know how to make sense of the outputs, are skeptical about their utility in patient care, are concerned that there are unacknowledged harms in FHH approaches, or simply face too many practical obstacles to make it seem worth the effort to integrate them into their routine practice.

Some of these issues run deeper than simply time constraints or the organization of data collection; they talk to the need for proponents of FHH tools to be clear about the value they will bring to colleagues who work in an often over-stretched system. A tool developer needs to begin with a clear articulation of its purpose, target user, factors likely to affect its implementation, and, crucially, see beyond the FHH component. These issues also need to be reflected in the evaluation of tools, and the focus on purposes should link naturally to identification of meaningful outcome measures.

Reviewing tools according to purpose is useful for underscoring the importance of considering purpose and attributes, but is nevertheless an artificial separation. The purposes of different tools could often be served from a common FHH 'platform'. We have deliberately approached this analysis from a primary care, generalist perspective, with an emphasis on challenges in practice and an implicit distinction from specialist genetics practice. While rejecting the view that effective continuing medical education is all that is required for family physicians to keep up with rapidly evolving fields like genetics, we nevertheless suggest that there are more similarities between the practice of clinical geneticists and family physicians than is usually acknowledged. Clinical geneticists are also generalists, are often required to make sense of ambiguous or incomplete information, often form an ongoing relationship with patients, and focus on families as well as individuals. A key difference between geneticists and family physicians is 
in the priority given to $\mathrm{FHH}$ as a diagnostic approach. Usually without technically sophisticated tools, geneticists develop a unified FHH 'platform' for each patient and use it for a range of purposes: genetic case finding, identifying special risks of complex disorders and encouraging decision-making to promote health. The formal use of the family systems genogram may be uncommon, but many of its attributes are part of the standard of care in genetic counseling.

In conclusion, we suggest that 'one size does not fit all', that there are several different uses to which FHH information may be put and that FHH tools have attributes which must vary according to these different purposes. We propose a framework which points to the need for thoughtfulness about the components of tools beyond the FHH information items and beyond a primary purpose of risk stratification. We suggest that looking outside the field of genetics, for example to cognitive psychology, may offer productive ways forward. Although one generic tool may not be capable of achieving all purposes, we believe that efficient platforms could be developed which facilitate multiple uses of $\mathrm{FHH}$ information in primary care settings.

\section{Acknowledgements}

Qendresa Hasanaj provided helpful discussions on the use of FHH information in complex disease risk assessment and shared examples of FHH incorporated into clinical practice guidelines. Silvia Visentin provided research administrative support for all aspects of this work. This review is part of the research program of the CIHR Emerging Team in Genomics in Screening (grant ETG 92254).

\section{References}

1 Berg AO, Baird MA, Botkin JR, Driscoll DA, Fishman PA, Guarino PD, Hiatt RA, Jarvik GP, Millon-Underwood S, Morgan TM, Mulvihill JJ, Pollin TI, Schimmel SR, Stefanek ME, Vollmer WM, Williams JK: National Institutes of Health State-of-the-Science Conference Statement: Family History and Improving Health. Ann Intern Med 2009;151:872-877.

-2 Guttmacher AE, Collins FS, Carmona RH: The family history - more important than ever. N Engl J Med 2004;351:2333-2336.

3 Feero WG, Bigley MB, Brinner KM; The Family Health History Multi-Stakeholder Workgroup of the American Health Information Community: New standards and enhanced utility for family health history information in the electronic health record: an update from the American Health Information Community's Family Health History Multi-Stakeholder Workgroup. J Am Med Inform Assoc 2008; 15:723-728.

-4 Reid GT, Walter FM, Brisbane JM, Emery JD: Family history questionnaires designed for clinical use: a systematic review. Public Health Genomics 2009;12:73-83.

5 Qureshi N, Modell B, Modell M: Timeline: raising the profile of genetics in primary care. Nat Rev Genet 2004;5:783-790.

6 Qureshi N, Carroll JC, Wilson B, Santaguida P, Allanson J, Brouwers M, Raina P: The current state of cancer family history collection tools in primary care: a systematic review. Genet Med 2009;11:495-506.

7 Qureshi N, Wilson B, Santaguida P, Carroll J, Allanson J, Ruiz Culebro C, Brouwers M, Raina P: Collection and use of cancer family history in primary care. Rockville, Agency for Healthcare Research and Quality, 2007, Report No 159.

-8 Wattendorf DJ, Hadley DW: Family history: the three-generation pedigree. Am Fam Physician 2005;72:441-448.

-9 Melton GB, Raman N, Chen ES, Sarkar IN, Pakhomov S, Madoff RD: Evaluation of family history information within clinical documents and adequacy of HL7 clinical statement and clinical genomics family history models for its representation: a case report. J Am Med Inform Assoc 2010;17:337340.

10 Rich EC, Burke W, Heaton CJ, Haga S, Pinsky L, Short P, Acheson L: Reconsidering the family history in primary care. J Gen Intern Med 2004;19:273-280.

11 Acheson LS, Wiesner GL, Zyzanski SJ, Goodwin MA, Stange KC: Family historytaking in community family practice: implications for genetic screening. Genet Med 2000;2:180-185.

12 Scheuner MT, de Vries H, Kim B, Meili RC, Olmstead SH, Teleki S: Are electronic health records ready for genomic medicine? Genet Med 2009;11:510-517.

13 Scheuner MT: Clinical application of genetic risk assessment strategies for coronary artery disease: genotypes, phenotypes, and family history. Prim Care 2004;31:711-737.

14 Carroll JC, Wilson BJ, Allanson J, Grimshaw J, Blaine SM, Meschino WS, Permaul JA, Graham ID: GenetiKit: a randomized controlled trial to enhance delivery of genetics services by family physicians. Fam Pract 2011;28:615-623.
15 Whelan AJ, Ball S, Best L, Best RG, Echiverri SC, Ganschow P, Hopkin RJ, Mayefsky J, Stallworth J: Genetic red flags: clues to thinking genetically in primary care practice. Prim Care 2004;31:497-508.

16 National Coalition for Health Professional Education in Genetics: Genetic red flags. http://www.nchpeg.org/index.php? option $=$ com_content $\&$ view $=$ article $\&$ id $=$ 59\&Itemid $=75$.

17 Green RF: Summary of workgroup meeting on use of family history information in pediatric primary care and public health. Pediatrics 2007;120(suppl 2):87-100.

18 Dolan SM, Moore C: Linking family history in obstetric and pediatric care: assessing risk for genetic disease and birth defects. Pediatrics 2007;120(suppl 2):66-70.

19 U.S. Preventive Services Task Force: Genetic risk assessment and BRCA mutation testing for breast and ovarian cancer susceptibility: recommendation statement. Ann Intern Med 2005;143:355-361.

20 Eaton L: GPs refer too many women for genetic tests. BMJ 2002;324:67.

21 White DB, Bonham VL, Jenkins J, Stevens N, McBride CM: Too many referrals of low-risk women for $B R C A 1 / 2$ genetic services by family physicians. Cancer Epidemiol Biomarkers Prev 2008;17:2980-2986.

22 Emery J, Morris H, Goodchild R, Fanshawe T, Prevost AT, Bobrow M, Kinmonth AL: The GRAIDS Trial: a cluster randomised controlled trial of computer decision support for the management of familial cancer risk in primary care. Br J Cancer 2007;97: 486-493. 
-23 Wilson BJ, Torrance N, Mollison J, Watson MS, Douglas A, Miedzybrodzka Z, Gordon R, Wordsworth S, Campbell M, Haites N, Grant A: Cluster randomized trial of a multifaceted primary care decision-support intervention for inherited breast cancer risk. Fam Pract 2006;23:537-544.

24 Yoon PW, Scheuner MT, Peterson-Oehlke KL, Gwinn M, Faucett A, Khoury MJ: Can family history be used as a tool for public health and preventive medicine? Genet Med 2002;4:304-310.

25 Ridker PM, Buring JE, Rifai N, Cook NR: Development and validation of improved algorithms for the assessment of global cardiovascular risk in women: the Reynolds Risk Score. JAMA 2007;297:611-619.

26 Hariri S, Yoon PW, Qureshi N, Valdez R, Scheuner MT, Khoury MJ: Family history of type 2 diabetes: a population-based screening tool for prevention? Genet Med 2006;8: 102-108.

27 Ruffin MT, Nease DE Jr, Sen A, Pace WD, Wang C, Acheson LS, Rubinstein WS, O’Neill S, Gramling R; Family Healthware Impact Trial FHITr Group: Effect of preventive messages tailored to family history on health behaviors: the Family Healthware Impact Trial. Ann Fam Med 2011;9:3-11.

28 Wilson B, Qureshi N, Little J, Santaguida P, Carroll J, Allanson J, Keshavarz H, Raina P: Clinical utility of cancer family history collection in primary care. Rockville, Agency for Healthcare Research and Quality, 2009, Report No 179.

29 Wilson BJ, Qureshi N, Santaguida P, Little J, Carroll JC, Allanson J, Raina P: Systematic review: family history in risk assessment for common diseases. Ann Intern Med 2009; 151:878-885.
30 Yoon PW, Scheuner MT, Jorgensen C, Khoury MJ: Developing Family Healthware, a family history screening tool to prevent common chronic diseases. Prev Chronic Dis 2009;6:1-11.

31 Etchegary H, Perrier C: Information processing in the context of genetic risk: implications for genetic-risk communication. J Genet Couns 2007; 16:419-432.

32 Chalmers K, Thomson K: Coming to terms with the risk of breast cancer: perceptions of women with primary relatives with breast cancer. Qual Health Res 1996;6:256-282.

33 McAllister M: Predictive genetic testing and beyond: a theory of engagement. J Health Psychol 2002; 7:491-508.

34 Kenen R, Ardern-Jones A, Eeles R: Family stories and the use of heuristics: women from suspected hereditary breast and ovarian cancer (HBOC) families. Soc Health Illn 2003 25:838-865.

35 Taylor DP, Hulse NC, Wood GM, Haug PJ, Williams MS: Ideal features for a patient-entered family history and risk assessment tool. AMIA Annu Symp Proc, November 2008, p 1152.

36 d'Agincourt-Canning L: The effect of experiential knowledge on construction of risk perception in hereditary breast/ovarian cancer. J Genet Couns 2005;14:55-69.

37 Hallowell N: Varieties of suffering: living with the risk of ovarian cancer. Health Risk Soc 2006;8:9-26.
38 McBride CM, Koehly LM, Sanderson SC, Kaphingst KA: The behavioral response to personalized genetic information: will genetic risk profiles motivate individuals and families to choose more healthful behaviors? Annu Rev Public Health 2010;31:89-103.

39 McGoldrick M, Gerson R: Genograms in Family Assessment. New York, WW Norton \& Co, 1985.

40 Jolly W, Froom J, Rosen MG: The genogram. J Fam Pract 1980;10:251-255.

41 Rakel RE (ed): Essentials of Family Practice. Philadelphia, WB Saunders Co, 1993.

42 Daly M, Farmer J, Harrop-Stein C, Montgomery S, Itzen M, Costalas JW, Rogatko A, Miller S, Balshem A, Gillespie D: Exploring family relationships in cancer risk counseling using the genogram. Cancer Epidemiol Biomarkers Prev 1999;8:393-398.

43 Eunpu DL: Systematically-based psychotherapeutic techniques in genetic counseling. J Genet Couns 1997;6:1-20.

44 Martin JR, Wilikofsky AS: Genetic counseling in primary care: longitudinal, psychosocial issues in genetic diagnosis and counseling. Prim Care 2004;31:509-524.

45 Werner-Lin A: Formal and informal support needs of young women with BRCA mutations. J Psychosoc Oncol 2008;26:111-133.

46 Starfield B: Primary Care. Balancing Health Needs, Services, and Technology. New York, Oxford University Press, 1998.

-47 Campbell M, Fitzpatrick R, Haines A, Kinmonth AL, Sandercock P, Spiegelhalter D, Tyrer P: Framework for design and evaluation of complex interventions to improve health. BMJ 2000;321:694-696.

48 Campbell NC, Murray E, Darbyshire J, Emery J, Farmer A, Griffiths F, Guthrie B, Lester $\mathrm{H}$, Wilson P, Kinmonth AL: Designing and evaluating complex interventions to improve health care. BMJ 2007;334:455-459. 